\title{
Correlation between Endoscopic and Histopathological Findings in Gastric Lesions. Sharma S, ${ }^{1}$ Makaju R, ${ }^{1}$ Dhakal R, ${ }^{1}$ Purbey B, ${ }^{2}$ Gurung RB, ${ }^{2}$ Shrestha ${ }^{3}$
}

\author{
${ }^{1}$ Department of Pathology \\ ${ }^{2}$ Department of Internal Medicine \\ ${ }^{3}$ Department of Pharmacology
}

Dhulikhel Hospital, Kathmandu University Hospital Kathmandu University School of Medical Sciences Dhulikhel, Kavre, Nepal.

\section{Corresponding Author}

Sujan Sharma

Department of Pathology,

Dhulikhel Hospital, Kathmandu University Hospital Kathmandu University School of Medical Sciences Dhulikhel, Kavre, Nepal.

E-mail: ssujans@hotmail.com

\section{Citation}

Sharma S, Makaju R, Dhakal R, Purbey B, Gurung $R B$, Shrestha R. Correlation between Endoscopic and Histopathological Findings in Gastric Lesions. Kathmandu Univ Med J 2015;51(3):216-9.

\section{ABSTRACT}

\section{Background}

Stomach is a common site for wide variety of lesions. The visualisation of the site with biopsy leads to the early detection of the pathologic process and appropriate therapy.

\section{Objectives}

The objective of this study is to correlate the histopathological pattern of endoscopic biopsies with distribution of gastric lesions according to age and sex.

\section{Method}

The retrospective study was carried out among 50 cases with endoscopic biopsies and histopathological assessment, received at Department of Pathology, Dhulikhel Hospital- Kathmandu University Hospital.

\section{Result}

Out of 50 cases majority of cases were of male gender with male: female ratio was 1.3:1. Our study showed a poor correlation between endoscopic and histopathological evidence of inflammation in the stomach. Two cases were diagnosed as intestinal metaplasia which were diagnosed as ulcer and erosion endoscopically. Out of $32 \%$ of cases diagnosed endoscopically as ulcer, only one case was confirmed histopathologically. Our study showed good correlation in the cases of carcinoma. Out of 17 cases diagnosed endoscopically as gastric carcinoma correlated histopathologically as gastric adenocarcinoma. Majority of carcinoma cases showed ulcerating fungating growth followed by ulcero-proliferative growth.

\section{Conclusion}

Endoscopy is incomplete without biopsy and histopathology is the gold standard for the diagnosis of endoscopically detected lesions. Endoscopic examination and histopathological examination of suspected gastric lesions should go parallel and neither should be a substitute of each other.

\section{KEY WORDS}

Carcinoma, endoscopy, helicobacterpylori, histopathology. 


\section{INTRODUCTION}

Human gastrointestinal tract which is long and tortuous is an important site for wide variety of lesions which includes congenital, inflammatory and neoplastic conditions. ${ }^{1-3}$ To facilitate diagnosis of different lesions, endoscopic and histology are complementary. ${ }^{4-6}$

Histopathological study of biopsy specimens are used to confirm endoscopic diagnosis in suspected malignancy or to rule out in the endoscopically benign appearing lesions and also are performed for monitoring the course, determining the extent of a disease as responses to therapy and for the early detection of complications. ${ }^{7-10}$ The aim of this study is to correlate the histopathological pattern of endoscopic biopsy with distribution of gastric lesions according to age and sex.

\section{METHODS}

The retrospective study was carried out among 50 cases with endoscopic biopsies and histopathological assessment, received from $1^{\text {st }}$ January 2014 onward at Department of Pathology, Dhulikhel Hospital- Kathmandu University Hospital.

Endoscopy was done in all the patient clinically diagnosed with gastric lesions and lesions were diagnosed on gross visualization during endosocopy. Patient of both the gender all ages, inpatients, outpatients and those with diagnostic gastric endoscopies were included in the study. Each endoscopic biopsy kept in a labeled bottle containing $10 \%$ neutral formalin was received in the department of pathology, Dhulikhel hospital. Gross examination of specimen according to the gross technique was done and documented. Tissue processing was done by using automatic tissue processor. Specimens were processed and embedded in paraffin wax and were cut into sections of 5 micrometer thickness all the slides were stained with Haematoxylin \& Eosin and with Giemsa stain whenever required. All the sections were reported by a pathologist and reviewed by another consultant pathologist. Data was collected and analyzed for frequency, percentages and results were presented through tables.

\section{RESULTS}

Among the 50 cases, $58 \%$ were male and $42 \%$ were females. The age and sex distribution of the study groups are shown in Table 1.

Out of five cases of erythematous patches diagnosed endoscopically, $40 \%$ were found to be normal, $20 \%$ as chronic gastritis and $40 \%$ were diagnosed Helicobacter pylori induced gastritis. Out of 16 cases which were diagnosed as gastric ulcer endoscopically, 25\% were found to be normal, $31 \%$ cases were diagnosed as chronic gastritis, $25 \%$ cases were diagnosed as Helicobacter pylori
Table 1. Age and sex distribution of study group

\begin{tabular}{|lccc|}
\hline Age(years) & Number & Male & Female \\
\hline $21-30$ & 4 & 2 & 2 \\
\hline $31-40$ & 7 & 6 & 1 \\
\hline $41-50$ & 10 & 5 & 5 \\
\hline $51-60$ & 10 & 7 & 3 \\
\hline $61-70$ & 9 & 2 & 7 \\
\hline$>71$ & 10 & 7 & 3 \\
\hline Total & 50 & $29(58 \%)$ & $21(42 \%)$ \\
\hline
\end{tabular}

induced gastritis and $6 \%$ of cases were diagnosed as ulcer, metaplasia and carcinoma respectively. Similarly, among 12 cases diagnosed as erosion endoscopically, 33\% were normal, 33\% showed Helicobacter pylori induced chronic gastritis, 25\% shows chronic gastritis and $8 \%$ showed metaplasia.(Table 2)

Table 2. Correlation between endoscopic and histopathological diagnosis

\begin{tabular}{|llllllll|}
$\begin{array}{l}\text { Endoscopic } \\
\text { Diagnosis }\end{array}$ & $\begin{array}{l}\text { Normal } \\
\text { study }\end{array}$ & Ulcer & $\begin{array}{l}\text { Gastri- } \\
\text { tis }\end{array}$ & $\begin{array}{l}\text { Meta- } \\
\text { plasia }\end{array}$ & $\begin{array}{l}\text { Carci- } \\
\text { noma }\end{array}$ & $\begin{array}{l}\text { H pylori } \\
\text { induced } \\
\text { gastritis }\end{array}$ & Total \\
\hline Erythema & $2(40 \%)$ & & $1(20 \%)$ & & & $2(40 \%)$ & $5(10 \%)$ \\
\hline Ulcer & $4(25 \%)$ & $1(6 \%)$ & $5(31 \%)$ & $1(6 \%)$ & $1(6 \%)$ & $4(25 \%)$ & $16(32 \%)$ \\
\hline Erosion & $4(33 \%)$ & & $3(25 \%)$ & $1(8 \%)$ & & $4(33 \%)$ & $12(24 \%)$ \\
\hline Growth & & & & & 17 & & $17(34 \%)$ \\
\hline Total & $10(20 \%)$ & $1(2 \%)$ & $9(18 \%)$ & $2(4 \%)$ & $18(36 \%)$ & $10(20 \%)$ & $50(100 \%)$ \\
\hline
\end{tabular}

However, all 17 of the endoscopically suspected carcinoma correlated histologically as adenocarcinoma, majority of carcinoma presented as an ulcerating fungating growth on endoscopy. (Table 3)

\section{Table 3. Endoscopic and histopathological findings of gastric} carcinoma.

\begin{tabular}{|lc|}
\hline Endoscopic findings & Adenocarcinoma \\
\hline Ulcerating fungating Growth & 6 \\
\hline Ulcero -proliferative Growth & 5 \\
\hline Friable Growth & 4 \\
\hline Nodular ulceration & 2 \\
\hline Total & 17 \\
\hline
\end{tabular}

\section{DISCUSSION}

The biopsy sampling of the gastric mucosa at diagnostic endoscopy provides useful information which helps in the diagnosis of various lesions. This study aimed toward finding a strong endoscopic and histological correlation of gastric lesions.

In our study majority of cases were of male. This gender ratio favoring males could be reflecting of the fact that males are exposed to more risk factors than females. ${ }^{11,12}$ 
Biopsies from each area with specific endoscopic diagnostic feature such as erythema, ulcer, erosions were examined to assess possible histological counterparts to these endoscopic findings. The severity of inflammation presence or absences of inflammatory cells, epithelial damage were compared. There was a poor correlation between endoscopic and histological evidence of inflammation in the stomach. Out of 16 cases diagnosed endoscopically as ulcer only one was diagnosed histologically. Most of the cases diagnosed endoscopically as erosion showed normal histological findings and remaining cases showed $\mathrm{H}$. Pylori induced gastritis. Mckenn and Appelman 13 observed only $50 \%$ correlation between erosion and its histological confirmation. ${ }^{13}$ Previous studies have also shown variation in results. ${ }^{14,15}$ This can be due to study conduct on different population and varying results of endoscopic and histological findings, misinterpretations during endoscopic, misinterpretations by histopathologist, sampling error between the actual site biopsied and the endoscopic abnormality. These all findings emphasized that the diagnosis of ulcer or gastritis should be based on histopathological examination of gastric mucosa. ${ }^{16,17}$

In our study two cases were found to have as intestinal metaplasia which were diagnosed as ulcer and erosion endoscopically. Intestinal metaplasia are premalignant gastric lesions and histopathological diagnosis of these lesions could be helpful to describe a group at high risk for gastric cancer. None of the patients showed features of gastric atrophy. ${ }^{18,19}$
Our study showed good correlation in the cases of carcinoma. Out of 17 cases diagnosed endoscopically as gastric carcinoma correlated histopathologically as gastric adenocarcinoma. Similar findings were found in other studies also. ${ }^{20}$ These findings recommended endoscopy and biopsy as valuable diagnostic procedure among patients suspecting gastric carcinoma. Used together they can eliminate the necessity for diagnostic laparotomy. Majority of carcinoma cases showed ulcerating fun gating growth followed by ulcero-proliferative growth. Study with similar findings have also been reported. ${ }^{21,22}$ In our study there was increase of incidence of carcinoma with increase of age.

Limitations of this study are the sampling errors and misinterpretation of endoscopic findings.

\section{CONCLUSION}

It was observed that endoscopic diagnosis of benign gastric lesions poorly correlated with those of histopathological diagnoses. Hence care should be taken for processing of the tissue and interpretation by the pathologist. Endoscopy is incomplete without biopsy and histopathology is the gold standard for the diagnosis of endoscopically detected lesions. Endoscopic examination and histopathological examination of suspected gastric lesions should go parallel and neither should be a substitute of each other.

\section{REFERENCES}

1. Ofmann JJ, Shaheen NJ, Desai AA, The quality of care in barrett's esophagus: Endoscopist and pathologist practices. Am J Gastroenterol. 2001;96:876-81.

2. McBroom HM, Ramsay AD. The clinicopathologicaal meeting: A means of auditing diagnostic performance. Am J Surg Pathol. 1993;17:75-80.

3. Dacosta RS, Wilson BC, Marcon NE. New optical technologies for earlier endoscopic diagnosis of premalignant gastrointestinal lesions. J Gastroenterol Hepatol. 2002;17:S86-S105.

4. Hopkins HH. Optical principles of endoscope. In: Berci G, ed. Endoscopy. $2^{\text {nd }}$ ed. New York: Appleton century grafts, 1976:3-26.

5. Versalovic J. Helicobacter pylori: Pathology and Diagnostic Strategies. Am J. Clin. Pathol 2003;119:403-12.

6. Vartanian RK, Leung JK et al. A novel Alcian yellow- toluidine blue stain for Helicobacter species: comparision with standars stains, a cost effectivenecc analysis and supplemetal utilities. Mod Pathol 1998;11-728.
7. Raao DN, Desai PB. Epidemiologicaal observation of cancer of the esophagus- A review of Indian studies. I J of cancer 1996;33:55-75.

8. Marson BC, Dawon IMP IN: Gastrointestinal Pathology. $2^{\text {nd }}$ ed. London: black Well scientific publications; 1998.148-51.

9. Dooley C.P. Background and historical considerations of Helicobacter pylori. Gastroenterology Clinics of North America 1993; 22:2-4.

10. Blaser M.J. heicobacter pylori and the pathogenesis of gastroduodenal inflammation. J of Inf Diseases 1990; 161:626-33.

11. Shennak MM, Tarawneh MS,Upper gastrointestinal diseases in symptomatic Jordanians: A prospective endoscopic study. Ann Saudi Med 1997;17(4):4711-74.

12. Paymaster JC, Sanghvi LD, Cancer of gastrointestinal tract in western India. Cancer 1968;21:279-87.

13. McKenna BJ, Appelman HD. Histopathology for the clinician-how to interpret biopsy information for gastritis. Gastroenterol Hepatol. 2006;3:165-71. 
14. Levy N, Stermer E. Accuracy of endoscopy in the diagnosis of inflamed gastric and duodenal mucosa; sr J Med Sci 1985 Jul; 21(7):564-8.

15. Calabrese $\mathrm{C}$ et al. Correlation between endoscopic features of gastric antrum, histology and Helicobacter Pylori Infection in adults. Ital J Gastro Hepato 1999 31(5):359-365.

16. Cotton $P B$, Price $A B$ et al. Preliminary evaluation of duodenitis by endoscopy and biopsy. Br Med J 1973;3:430-3.

17. Grace H. Elta, Henry D et al. A study of the correlation between endoscopic and histological diagnoses in gastroduodenitis. The Am J of Gastroenterology 1987 82(8): 749-53.

18. Muller LB, Fagundes RB, A Prevalence of Helicobacter pylori infection and gastric cancer precursor lesions in patients with dyspepsia. Arq Gastroenterol. 2007 44(2):93-8.
19. Joo YE, Park HK. Prevalence and risk factors of atrophic gastritis and intestinal metaplasia: a nationwide multicenter prospective study in Korea. Gut liver: 2013(3):303-10.

20. Hecker R, Fitch R. The value of endoscopy and biopsy in the diagnosis of gastric carcinoma. Med J Aust. 1975 Sep 20:2(12):472-4.

21. Pailoor K, Sarpangala MK. Istopathological diagnosis of gastric biopsies in correlation with endoscopy- A study in a tertiary care center. Adv lab Med Int 2012;3(2):22-31.

22. Qizibash AH, Stevenson GW. Early gastric cancer in:Pathology Annals. New York: Appleton-Century-Crofts;1979:14-24. 